\title{
One-year outcomes of rosuvastatin versus placebo in sepsis-associated acute respiratory distress syndrome: prospective follow-up of SAILS randomised trial
}

\author{
Victor D Dinglas, ${ }^{1,2}$ Ramona 0 Hopkins, ${ }^{3,4,5}$ Amy W Wozniak ${ }^{1,6}$ Catherine L Hough, $^{7}$ \\ Peter E Morris, ${ }^{8}$ James C Jackson, ${ }^{9}$ Pedro A Mendez-Tellez, ${ }^{1,10}$ \\ 0 Joseph Bienvenu, ${ }^{1,11}$ E Wesley Ely, ${ }^{9,12}$ Elizabeth Colantuoni, ${ }^{1,6}$ \\ Dale M Needham ${ }^{1,2,13}$
}

\begin{abstract}
- Additional material is published online only. To view please visit the journal online (http://dx.doi.org/10.1136/ thoraxjnl-2015-208017).
\end{abstract}

For numbered affiliations see end of article.

\section{Correspondence to} Dr Dale Needham, Division of Pulmonary and Critical Care Medicine, Johns Hopkins University, $1830 \mathrm{E}$. Monument St, 5th Floor, Baltimore, MD 21205, USA;

dale.needham@jhmi.edu

Received 2 November 2015 Revised 7 January 2016 Accepted 5 February 2016 Published Online First 2 March 2016

\section{SLinked}

- http://dx.doi.org/10.1136/ thoraxjnl-2016-208466

CrossMark

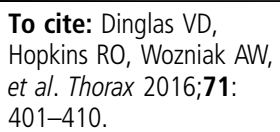

\section{ABSTRACT}

Background Prior randomised trials have evaluated statins in patients with sepsis and acute respiratory distress syndrome (ARDS), but there has been no comprehensive evaluation of long-term effects, despite potential neuromuscular and mental health adverse effects of these drugs.

Aim To evaluate the effect of rosuvastatin versus placebo on survival, physical function and performance, and mental health outcomes in patients with sepsisassociated ARDS.

Methods Prospective follow-up evaluation of the ARDS Clinical Trials Network Statins for Acutely Injured Lungs from Sepsis trial of rosuvastatin versus placebo in 568 mechanically ventilated patients with sepsis-associated ARDS, with blinded 6-month outcome assessment performed in the 272 eligible survivors for age-adjusted and sex-adjusted 36-Item Short Form Health Survey (SF36) physical function and mental health domains, and in 84 eligible survivors for the 6 min walk test, along with secondary outcomes evaluations of survival, and additional patient-reported and performance-based measures at 6-month and 12-month follow-up.

Results Over 1-year follow-up, there was no significant difference in cumulative survival in the rosuvastatin versus placebo groups ( $58 \%$ vs $61 \% ; p=0.377$ ), with survivors demonstrating substantial impairments in physical function and mental health. Rosuvastatin versus placebo had no effect (mean treatment effect $(95 \% \mathrm{CI})$ ) on SF-36 physical function (0 ( -7 to 8$), p=0.939)$ or mental health $(-6(-12$ to 1) $p=0.085)$ domains, $6 \mathrm{~min}$ walk distance (per cent predicted: 2 (-9 to 14), $p=0.679$ ) or the vast majority of secondary outcomes. Conclusions Over 1-year follow-up, patients with sepsis-associated ARDS had high cumulative mortality, with survivors commonly experiencing impairments in physical functioning and performance, and mental health. Randomisation to rosuvastatin had no effect on these outcomes.

Trial registration number NCT00979121 and NCT00719446.

\section{INTRODUCTION}

In sepsis-associated acute respiratory distress syndrome (ARDS), rosuvastatin versus placebo was

\section{Key messages}

What is the key question?

- Does rosuvastatin use in the intensive care unit affect long-term survival, and physical and mental health outcomes in patients with sepsis-associated acute respiratory distress syndrome (ARDS)?

What is the bottom line?

- Over 6-month and 12-month follow-up, there is no evidence from this study that randomisation to rosuvastatin had any effects on survival, physical functioning and performance and mental health outcomes.

\section{Why read on?}

- These patients with sepsis-associated ARDS had high cumulative mortality, with survivors commonly experiencing impairments in physical functioning and performance, mental health and quality of life, further highlighting the need for novel interventions to mitigate these impairments.

tested in a large, multicentre, randomised study, Statins for Acutely Injured Lungs from Sepsis (SAILS) trial. This trial, conducted by the NHLBI ARDS Clinical Trials Network (ARDSNet), reported no significant difference in short-term mortality and ventilator-free days. ${ }^{1}$ This study exemplifies the great interest in evaluating 3-hydroxy-3-methylglutaryl coenzyme A reductase inhibitors (statins) in patients with sepsis, ARDS and other critical illness, with at least 10 additional randomised trials conducted. ${ }^{2-5}$ Despite such interest, there has been no comprehensive evaluation of potential benefits and risks of statins beyond 90-day follow-up.

Importantly, in addition to their hypothesised beneficial pleiotropic effects, statins have known toxicity to liver and skeletal muscle, even when administered for a short time. ${ }^{6}$ In the SAILS trial, 
patients randomised to rosuvastatin had significantly fewer hepatic and renal failure-free days, and higher serum levels of aspartate aminotransferase, with some having concurrent elevations of creatine kinase and alanine aminotransferase indicating potential muscle and/or liver toxicity. ${ }^{1}$ Moreover, in an ancillary study, a subgroup of SAILS patients underwent blinded electromyography and nerve conduction studies, finding increased prevalence of neuromyopathy in rosuvastatin versus placebo group at study day $7 \quad(63 \%$ vs $33 \%, \quad \mathrm{p}=0.05){ }^{7}$ Any rosuvastatin-associated neuromuscular injury may exacerbate other forms of muscle injury and wasting commonly occurring early during critical illness. ${ }^{8}$ Hence, assessing for long-term neuromuscular and related physical effects of statin administration in the intensive care unit (ICU) is important. ${ }^{1}$

In addition to these physical effects, statins have known adverse mental health effects, including depression, nightmares and paranoia that may be more common in patients with other mental health impairments. ${ }^{9}$ Notably, patients with ARDS have a high prevalence and co-occurrence of mental health impairments before, during and after their ICU stay, ${ }^{10}{ }^{11}$ including incident post-traumatic stress disorder (PTSD) symptoms associated with nightmares and flashbacks to frightening ICU memories. ${ }^{12}$ Such post-ICU mental health impairments might be exacerbated if exposure to statins caused nightmares or paranoia in the ICU.

Finally, prior randomised trials in sepsis and ARDS have demonstrated that both non-significant and significant differences in short-term mortality may markedly change over 6-month to 12 -month follow-up; ${ }^{13}{ }^{14}$ underscoring the need for monitoring of survival beyond 60-day to 90-day follow-up. ${ }^{15}$ Such monitoring is especially important since organ failure ${ }^{16}$ and neuromuscular dysfunction ${ }^{17}$ in the ICU are associated with mortality up to 1-year later and these factors differed between treatment groups in SAILS, with SAILS demonstrating a non-significant increase in in-patient mortality up to 60 days after randomisation (rosuvastatin vs placebo: $28.5 \%$ vs $24.9 \%, \mathrm{p}=0.21)^{1}$

Given above rationale, via the ARDSNet Long-Term Outcomes Study (ALTOS), we conducted a prospective longitudinal evaluation of SAILS patients' outcomes over 6-month and 12-month follow-up to evaluate the effect of rosuvastatin versus placebo on physical function and performance, mental health and survival.

\section{METHODS}

Consenting patients from 35 of 37 hospitals participating in SAILS were eligible for phone-based, patient-reported outcomes assessments as part of this prospective, longitudinal follow-up study. At 23 of these hospitals, due to funding issues, recruitment stopped for $\geq 7$ months (December 2011 to July 2012). In addition to phone-based assessments, patients from 12 of the 35 hospitals were also recruited for in-person physical performance assessments. Patient follow-up occurred from 2010 to late 2014. Each participating site's institutional review boards approved this study. Informed consent was obtained from each patient or his/her proxy (if patient was incapable of consent).

\section{Patients}

SAILS eligibility criteria and study intervention have been reported previously, and summarised briefly herein. ${ }^{1}$ Patients were randomised (stratified by hospital site) to receive either enteral rosuvastatin or placebo until the earliest of 3 days after ICU discharge, study day 28 or death. These patients were managed with fluid conservative and lung-protective ventilation protocols, with similar average fluid balances and tidal volumes for both treatment groups. ${ }^{1}$ SAILS was stopped for futility after 745 of 1000 patients were enrolled, with no significant differences in short-term mortality, ventilator-free days and ICU-free days. In recruiting SAILS participants for follow-up via the ALTOS study, the following additional exclusion criteria were applied: $<18$ years old, non-English speaking, homeless or cognitively impaired, evaluated based on patients' status prior to hospitalisation using medical record review and/or interview with the patient and/or proxy. The first 75 SAILS patients enrolled into this follow-up study were co-enrolled in the ARDSNet EDEN (Early vs. Delayed Enteral Nutrition) trial, which evaluated initial trophic versus full enteral feeding up to 6 days after ARDS, and demonstrated no significant differences in short-term outcomes or 6-month and 12-month physical function and performance, mental health and survival. ${ }^{18-20}$

\section{Study procedures}

At 6-month and 12-month follow-up, research personnel, blinded to treatment allocation, completed study assessments via phone (details in 'Patient-reported outcomes-physical function and mental health symptoms' section). Loss to follow-up was minimised by using established cohort retention methodology. ${ }^{21}$ If unable to complete the study assessment via phone, surveys were completed by mail (6\% of all assessments at the 6-month primary outcome time-point) and/or by designated proxies (only for two secondary outcome measures, the Functional Performance Inventory (FPI)-Short Form and Employment status, representing $12 \%$ of these 6 -month assessments).

For patients undergoing in-person physical performance assessments at 6-month and 12-month follow-up, research staff, blinded to treatment allocation, collected baseline comorbidity status (using the Functional Comorbidity Index ${ }^{22}$ ) from the medical record and completed testing (details in 'Performancebased physical assessments' section).

\section{Primary and secondary outcomes}

Patient-reported outcomes-physical function and mental health symptoms

The primary patient-reported outcomes were the age-adjusted and sex-adjusted physical function and mental health domain scores of the Medical Outcomes Study Short Form 36 V.2 (SF-36) instrument ${ }^{23}$ (range: 0-100; higher score is better) at 6-month follow-up, with 12 -month scores as a secondary outcome.

Other secondary outcomes, at 6-month and 12-month follow-up, included: SF-36 physical and mental health summary normalised scores (mean $=50 ; \mathrm{SD}=10$; higher score is better); the EQ-5D-3L ${ }^{24}$ generic quality of life instrument utility score ${ }^{25}$ (range: -0.11 to 1.0 ; higher score is better) and visual analogue scale score (range: 0-100; higher score is better); the FPI-Short Form ${ }^{26}$ overall functional activity score and subscale scores for physical exercise, maintaining household and body care (for each, range: 0-3; higher score is better); Hospital Anxiety and Depression Scale $(\mathrm{HADS})^{27}$ subscale scores for anxiety and depression symptoms (for each, range: $0-21$; lower score is better, with scores $\geq 8$ indicating substantial symptoms); Impact of Events Scale-Revised for PTSD symptoms (range: 0-4; lower score is better, with scores $\geq 1.6$ indicating substantial symptoms $^{28}$ ) and employment status (full-time or part-time work vs unemployed). ${ }^{18}$

\section{Performance-based physical assessments}

For the subset of patients undergoing physical performance assessments, the primary outcome was the 6-month, 6 min walk 
test, evaluated as a per cent of the predicted value, ${ }^{29}$ with 12 -month values as a secondary outcome.

Other secondary physical performance outcomes, at 6-month and 12-month follow-up, included: $4 \mathrm{~m}$ gait speed $(\mathrm{m} / \mathrm{s}) ;^{30}$ manual muscle testing using the Medical Research Council sumscore (range: $0-60 ;<48$ indicating 'ICU-acquired weakness ${ }^{31}$ ); per cent of predicted value for hand grip strength, ${ }^{32}$ maximal inspiratory pressure, ${ }^{33} \mathrm{FEV}_{1}$, and $\mathrm{FVC}^{34}$ body mass index (BMI) and per cent fat and muscle areas based on upper arm anthropometric assessment. ${ }^{35}$

\section{Statistical analyses}

Baseline patient and intensive care variables were compared between the two treatment groups using counts and percentages, or means and SDs. The Kaplan-Meier method was used to estimate the cumulative proportion of survivors throughout the follow-up period separately for rosuvastatin and placebo groups, and compared using the log-rank test. Patients ineligible for follow-up were censored at hospital discharge and those with unknown mortality at 12 months censored at 6 months. At each follow-up, the mean and the odds of the continuous and binary outcomes, respectively, were estimated using linear and logistic random intercept regression models, including main effect of follow-up time-point (12 vs 6 months). The patient-reported primary outcomes (ie, 6-month SF-36 physical function and mental health domains) were compared across treatment groups using linear regression with the main effect of treatment, adjusting for sex and age (using a linear spline with a knot at 50 years old due to a non-linear association of age with outcomes). ${ }^{36}$ The physical performance primary outcome (ie, 6 min walk test per cent predicted score at 6-month assessment) was compared across treatment groups using linear regression with the main effect of treatment only.

A series of sensitivity analyses for the primary outcomes were completed. First, patients who consented, but died prior to 6 months were included with their outcome value set to the worst possible value. In addition, the Wilcoxon U statistic was computed after ranking the patients by their outcome score with death assigned the worst rank. ${ }^{37}$ Second, the linear regression models were expanded to also adjust for ARDS risk factor (pneumonia vs other), Acute Physiology and Chronic Health Evaluation III (APACHE III) score, Alcohol Use Disorders Identification Test score in the patient-reported outcome regression model and for BMI, and Functional Comorbidity Index, APACHE III and baseline SF-36 PF domain scores (obtained retrospectively) for the physical performance outcomes. Third, the regression models were extended to include a statistical interaction term to explore possible effect modification of the SAILS and EDEN randomised assignments.

Analysis of secondary outcomes compared the mean or the odds for continuous and binary outcomes across the two treatment groups, separately at 6-month and 12-month follow-up, using linear or logistic random intercept regression models, respectively. The models included main effects of treatment group and follow-up time-point (12 vs 6 months) and their interaction. Age and sex were included in the models using

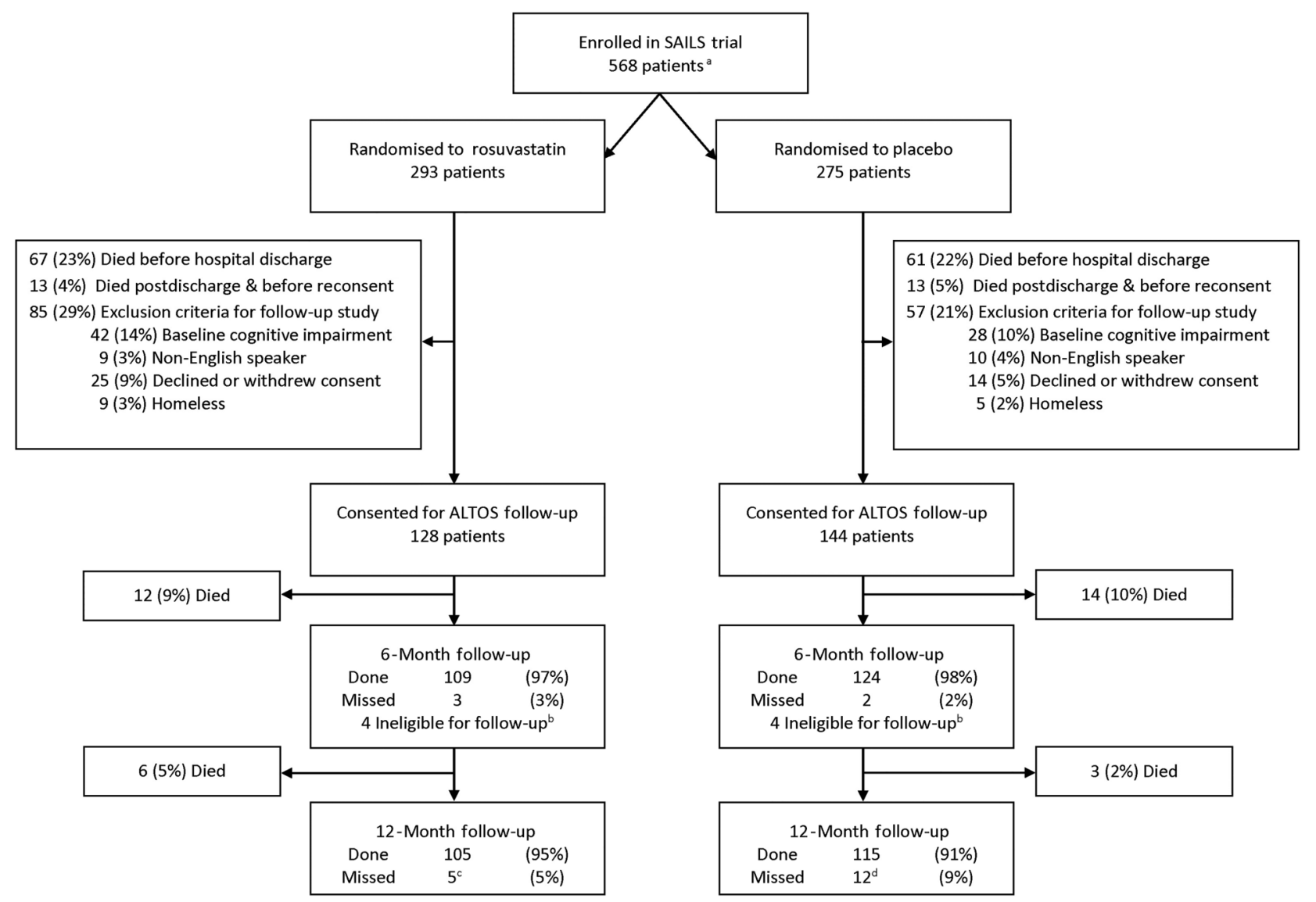

Figure 1 Enrolment and follow-up. 'aess than the 745 patient sample size of the SAILS trial due to two sites not participating in this study and a temporary cessation of recruitment into this study. ${ }^{b}$ Eight eligible patients were missed due to temporary cessation of recruitment for $\geq 7$ months for the majority of study sites. ' Four of these five patients were alive at 12 months and one was censored for survival analysis. ${ }^{d}$ Twelve patients were alive at 12 months. ALTOS, ARDSNet Long-Term Outcomes Study; SAILS, Statins for Acutely Injured Lungs from Sepsis. 
SF-36 data. For sensitivity analysis, these secondary analyses were repeated including patients who consented, but died prior to the 6-month or 12-month follow-up, as previously described.

Several a priori subgroup analyses of the treatment effect were performed for all primary and secondary outcomes. The following subgroups were evaluated: age (continuous), APACHE III (continuous), baseline BMI $(<30, \geq 30)$, ARDS subgroup $\left(\mathrm{PaO}_{2} / \mathrm{FiO}_{2} \leq 200\right.$ vs $\left.>200\right)$, shock at baseline (present vs absent) and statin use immediately prior to hospitalisation (yes vs no). For physical performance outcomes, additional subgroups included: sex, an indicator for the patient being in the ICU on study day 7 (reflecting more prolonged exposure to rosuvastatin under the SAILS protocol), Functional Comorbidity Index, baseline FPI survey score (retrospectively obtained) and baseline SF-36 PF domain score (normed; retrospectively obtained). The subgroup analyses were fit using the same, previously described, random intercept regression models, but included the subgroup variable and the following interactions: (1) treatment group and subgroup variable, (2) time and subgroup variable and (3) time, subgroup variable and treatment group. A post-hoc analysis compared the primary outcomes between patients in highest quartile of decrease in $\mathrm{C}$ reactive protein (CRP) levels and those in the lowest quartile. Additionally, we also completed a single post-hoc sensitivity analyses to explore clustering effects by hospital site by adding a random intercept for hospital to the statistical models.

The parent trial for this study (SAILS trial) was designed with $92 \%$ power to detect a $9 \%$ absolute difference in mortality comparing rosuvastatin versus a placebo control $(18 \%$ vs $27 \%$, respectively), with a sample size of 1000 patients. However, the trial was stopped for futility after enrolling 745 patients. For this prospective, longitudinal follow-up study of the SAILS trial, it was hypothesised that rosuvastatin would be harmful relative to placebo; however, there was no a priori effect size

Table 1 Baseline characteristics and intensive care data*

\begin{tabular}{|c|c|c|c|c|c|c|c|c|}
\hline & \multicolumn{2}{|c|}{ Entire SAILS cohort $†$} & \multicolumn{2}{|c|}{ Eligible for ALTOS $\ddagger$} & \multicolumn{2}{|c|}{$\begin{array}{l}\text { Patient-reported outcomes } \\
\text { evaluation§ }\end{array}$} & \multicolumn{2}{|c|}{$\begin{array}{l}\text { Performance-based } \\
\text { physical outcomes } \\
\text { evaluation§ }\end{array}$} \\
\hline & $\begin{array}{l}\text { Rosuvastatin } \\
(\mathrm{n}=379)\end{array}$ & $\begin{array}{l}\text { Placebo } \\
(n=366)\end{array}$ & $\begin{array}{l}\text { Rosuvastatin } \\
(\mathrm{n}=293)\end{array}$ & $\begin{array}{l}\text { Placebo } \\
(n=275)\end{array}$ & $\begin{array}{l}\text { Rosuvastatin } \\
(n=128)\end{array}$ & $\begin{array}{l}\text { Placebo } \\
(n=144)\end{array}$ & $\begin{array}{l}\text { Rosuvastatin } \\
(\mathrm{n}=36)\end{array}$ & $\begin{array}{l}\text { Placebo } \\
(n=48)\end{array}$ \\
\hline \multicolumn{9}{|l|}{ Baseline patient data } \\
\hline Age, years & $54(17)$ & $54(16)$ & $53(18)$ & $54(15)$ & $50(16)$ & $52(14)$ & 49 (14) & $50(15)$ \\
\hline Women, No (\%) & $195(51)$ & $185(51)$ & $145(49)$ & $139(51)$ & $68(53)$ & $75(52)$ & $13(36)$ & $27(56)$ \\
\hline White, No (\%) & $301 / 365(82)$ & 289/356 (82) & $240 / 288(83)$ & $211 / 267(79)$ & $107 / 126(85)$ & $122 / 141(87)$ & $31 / 35(89)$ & $42 / 47(89)$ \\
\hline $\mathrm{BMI}, \mathrm{kg} / \mathrm{m}^{2}$ & $31.0(9.9)$ & $30.4(10.1)$ & $31(9.5)$ & $30.1(10)$ & $31.4(10)$ & $31.5(10)$ & $35.5(14)$ & $29.7(8)$ \\
\hline Diabetes, No (\%) & $84(22)$ & $86(24)$ & $60(20)$ & $67(24)$ & $25(20)$ & $37(26)$ & $6(17)$ & $6(13)$ \\
\hline \multicolumn{9}{|l|}{ Baseline intensive care data } \\
\hline Medical ICU admission, No (\%) & $330(87)$ & $317(87)$ & $253(86)$ & $239(87)$ & $108(84)$ & $124(86)$ & $28(78)$ & $40(83)$ \\
\hline APACHE III score & $92(28)$ & $95(28)$ & $91(29)$ & $93(28)$ & $87(27)$ & $89(28)$ & $82(29)$ & $84(30)$ \\
\hline $\mathrm{PaO}_{2} / \mathrm{FiO}_{2}$ ratio $(\mathrm{mm} \mathrm{Hg})$ & $170(71)$ & $170(67)$ & $171(73)$ & $171(67)$ & $171(71)$ & $165(66)$ & $182(74)$ & $160(56)$ \\
\hline $\begin{array}{l}\mathrm{PaO}_{2} / \mathrm{FiO}_{2} \text { ratio } \leq 200(\mathrm{~mm} \mathrm{Hg}) \text {, } \\
\text { No }(\%)\end{array}$ & 267/371 (72) & 253/361 (70) & 209/289 (72) & 189/272 (69) & $91 / 127(72)$ & 104/143 (73) & 25/36 (69) & $39 / 48(81)$ \\
\hline Baseline shock, No (\%) & $173(46)$ & $166(45)$ & $131(45)$ & $119(43)$ & $50(39)$ & $55(38)$ & $15(42)$ & $22(46)$ \\
\hline \multicolumn{9}{|c|}{ Primary lung injury risk factor, № (\%) } \\
\hline Pneumonia & 267/377 (71) & 260/365 (71) & 200/291 (69) & $202 / 274(74)$ & $88 / 128(69)$ & 107/143 (75) & 21/36 (58) & $35 / 48(73)$ \\
\hline Non-pulmonary infection & 72/377 (19) & $73 / 365(20)$ & $58 / 291(20)$ & 49/274 (18) & $30 / 128(23)$ & 25/143 (17) & 11/36 (31) & $11 / 48(23)$ \\
\hline Aspiration & $26 / 377(7)$ & $23 / 365(6)$ & 23/291 (8) & $16 / 274(5)$ & $9 / 128(7)$ & $7 / 143(5)$ & $4 / 36(11)$ & $1 / 48(2)$ \\
\hline Other & 12/377 (3) & 9/365 (2) & 10/291 (4) & 7/274 (3) & $1 / 128(1)$ & 4/143 (3) & 0/36 (0) & $1 / 48(2)$ \\
\hline \multicolumn{9}{|l|}{ Organ failure-free days to day $14 \uparrow$} \\
\hline Cardiovascular & $9(5)$ & $9(5)$ & $9(5)$ & $9(5)$ & $11(3)$ & $10(4)$ & $10(3)$ & $10(4)$ \\
\hline Renal & $10(5)$ & $11(5)$ & $11(5)$ & $11(4)$ & $12(5)$ & $13(3)$ & $11(5)$ & $13(3)$ \\
\hline Hepatic & $11(5)$ & $12(4)$ & $11(5)$ & $12(4)$ & $12(4)$ & $13(3)$ & $12(4)$ & $13(3)$ \\
\hline Coagulation & $11(5)$ & $11(5)$ & $11(5)$ & $12(4)$ & $12(4)$ & $13(3)$ & $13(3)$ & $13(3)$ \\
\hline Ventilator-free days to day $28^{* *}$ & $15(11)$ & $15(11)$ & $16(11)$ & $15(11)$ & $20(7)$ & $20(7)$ & $20(6)$ & $20(8)$ \\
\hline ICU-free days to day 28 & $14(10)$ & $14(10)$ & $15(10)$ & $15(10)$ & $19(7)$ & $19(8)$ & $19(8)$ & $18(8)$ \\
\hline
\end{tabular}

*Figures are means (SD) unless stated otherwise. Proportions might not add to $100 \%$ because of rounding. Median (Q1, Q3) values for continuous variables for the rosuvastatin versus placebo for the 'eligible for ALTOS' subset are age: $54(40,66)$ vs $54(43,64), \mathrm{BMI}: 30(25,35)$ vs $28(23,34), \mathrm{APACHE}^{\mathrm{III}}$ score: $91(69,109)$ vs $90(73,112), \mathrm{PaO} / \mathrm{FiO}{ }_{2}$ ratio: 163 $(120,205)$ vs $163(124,216)$, ventilator-free days to day $28: 20(0,25)$ vs $20(0,25)$, ICU-free days to day $28: 19(4,24)$ vs $18(2,24)$, for the 'patient-reported outcomes evaluation' subset are age: $52(37,62)$ vs $53(43,61)$, BMl: $30(25,36)$ vs $29(25,36)$, APACHE III score: $84(68,105)$ vs $86(70,107), \mathrm{PaO}_{2} / \mathrm{FiO}$, ratio: 161 $(120,208)$ vs 153 (118, 210),

ventilator-free days to day $28: 23(18,25)$ vs $23(18,26)$, ICU-free days to day $28: 22(16,24)$ vs $21(16,25)$, for the 'performance-based physical outcomes evaluation' subset are age: $51(37,59)$ vs $52(41,58)$, BMI: $35(26,40)$ vs $27(25,33)$, APACHE III score: $80(59,104)$ vs $79(65,104), \mathrm{PaO}_{2} / \mathrm{FiO}_{2}$ ratio: $162(132,216)$ vs $158(116,192)$, ventilator-free days to day 28: $23(15,26)$ vs $24(17,26)$, ICU-free days to day $28: 22(14,25)$ vs $21(15,25)$.

tThe entire cohort of the SAILS trial ${ }^{1}$ presented alongside cohorts evaluated in this prospective follow-up study.

fLess than the 745 patient sample size of the SAILS trial due to two sites not participating in this study and a temporary cessation of recruitment into this study.

$\S$ Eligible patients from 35 hospitals were recruited for phone-based assessment of patient-reported outcomes. In 12 of these 35 hospitals, patients were also recruited for in-person assessment of their physical performance.

१Data presented as overall average for each patient's mean value of available daily data. Corticosteroids data available until earlier of $48 \mathrm{~h}$ after cessation of mechanical ventilation or day 7. Vasopressor data available until earlier of death, study hospital discharge or day 14. Proportions calculated among days in ICU in which medication data were available. Days without organ failure until day 14 calculated as previously published.

** Those who died before day 28 were assigned 0 ventilator-free days.

ALTOS, ARDSNet Long-Term Outcomes Study; APACHE III, Acute Physiology and Chronic Health Evaluation III; BMI, body mass index; FiO 2 , fraction of inspired oxygen; ICU, intensive care unit; $\mathrm{PaO}_{2}, \mathrm{pO}_{2}$ in arterial blood; SAILS, Statins for Acutely Injured Lungs from Sepsis. 
Table 2 Six-month and 12-month patient-reported and performance-based physical outcomes for all patients*

\begin{tabular}{|c|c|c|c|c|}
\hline Patient-reported outcome domain—survey instrument $\dagger$ & 6 months $(n=233)$ & 12 months $(n=220)$ & Difference $\ddagger(95 \% \mathrm{Cl})$ & $\mathrm{p}$ Value $\neq$ \\
\hline \multicolumn{5}{|l|}{ Quality of life-SF-36 } \\
\hline Physical function (norm: 81 (10)) & $49(32)$ & $52(32)$ & $4(1$ to 6$)$ & 0.005 \\
\hline Physical health summary (norm: 50 (10)) & $37(12)$ & $39(13)$ & $2(1$ to 3$)$ & 0.003 \\
\hline Mental health (norm: $76(3))$ & $64(25)$ & $65(26)$ & $0(-3$ to 2$)$ & 0.757 \\
\hline Mental health summary (norm: 50 (10)) & $45(15)$ & $45(15)$ & $0(-2$ to 2$)$ & 0.923 \\
\hline \multicolumn{5}{|l|}{ Quality of life-EQ-5D } \\
\hline Utility score & $0.68(0.24)$ & $0.69(0.26)$ & $0.01(-0.02$ to 0.03$)$ & 0.657 \\
\hline Visual analogue scale & $67(22)$ & $71(21)$ & $4(1$ to 7$)$ & 0.004 \\
\hline \multicolumn{5}{|l|}{ Functional activities-Functional Performance Inventory-Short Form } \\
\hline Overall score & $1.9(0.7)$ & $2.0(0.7)$ & 0.1 (0.0 to 0.2$)$ & 0.037 \\
\hline Physical exercise subscale & $1.5(0.9)$ & $1.6(0.9)$ & $0.1(0.0$ to 0.2$)$ & 0.062 \\
\hline Maintaining house subscale & $1.7(0.9)$ & $1.9(0.9)$ & $0.1(0.0$ to 0.2$)$ & 0.006 \\
\hline Body care subscale & $2.5(0.7)$ & $2.5(0.6)$ & $0.1(0.0$ to 0.1$)$ & 0.152 \\
\hline \multicolumn{5}{|l|}{ Mental health symptoms } \\
\hline Anxiety score-HADS & $7(5)$ & $7(5)$ & $0(-1$ to 0$)$ & 0.340 \\
\hline Anxiety $\geq 8$, No (\%) & $100(46)$ & $84(41)$ & $-6 \%(-18$ to 6$)$ & 0.343 \\
\hline Depression score-HADS & $6(5)$ & $6(5)$ & 0 (0 to 1$)$ & 0.523 \\
\hline Depression $\geq 8$, No (\%) & $81(37)$ & $76(37)$ & $0 \%(-11$ to 11$)$ & 0.981 \\
\hline Post-traumatic stress disorder score-IES-R & $1.1(0.9)$ & $1.0(1.0)$ & $0.0(-0.1$ to 0.1$)$ & 0.418 \\
\hline Post-traumatic stress disorder $\geq 1.6$, No (\%) & $55(25)$ & $52(26)$ & $1 \%(-8$ to 9$)$ & 0.855 \\
\hline Employed, No (\%)§ & $42(19)$ & $50(24)$ & $3 \%(-1$ to 7$)$ & 0.123 \\
\hline Performance-based physical outcomes $\dagger$ & 6 months $(n=67)$ & 12 months $(n=55)$ & Difference $(95 \% \mathrm{Cl})$ & $\mathrm{p}$ Value \\
\hline 6 min walk distance, \% predicted & $65(24)$ & $71(23)$ & 7 (3 to 11$)$ & 0.001 \\
\hline $4 \mathrm{~m}$ gait speed $(\mathrm{m} / \mathrm{s})$ & $0.9(0.3)$ & $1.0(0.3)$ & $0.1(0.0$ to 0.1$)$ & 0.004 \\
\hline Manual muscle test score & $57(4)$ & $57(4)$ & $0(0$ to 1$)$ & 0.296 \\
\hline Hand grip strength, $\%$ predicted & $83(29)$ & $91(32)$ & $8(4$ to 12$)$ & 0.001 \\
\hline Maximal inspiratory pressure, $\%$ predicted & $85(32)$ & $98(32)$ & 12 (6 to 18$)$ & $<0.001$ \\
\hline $\mathrm{FEV}_{1} \%$ predicted & $77(21)$ & $80(21)$ & $1(-1$ to 4$)$ & 0.407 \\
\hline FVC \% predicted & $77(20)$ & $79(19)$ & $0(-2$ to 2$)$ & 0.991 \\
\hline BMI $\left(\mathrm{kg} / \mathrm{m}^{2}\right)$ & $29(8)$ & $30(10)$ & $1(0$ to 1$)$ & 0.027 \\
\hline Arm fat area, $\%$ & $35(12)$ & $36(12)$ & $1(-1$ to 2$)$ & 0.198 \\
\hline Arm muscle area, \% & $53(10)$ & $53(10)$ & $-1(-2$ to 1$)$ & 0.366 \\
\hline \multicolumn{5}{|c|}{ 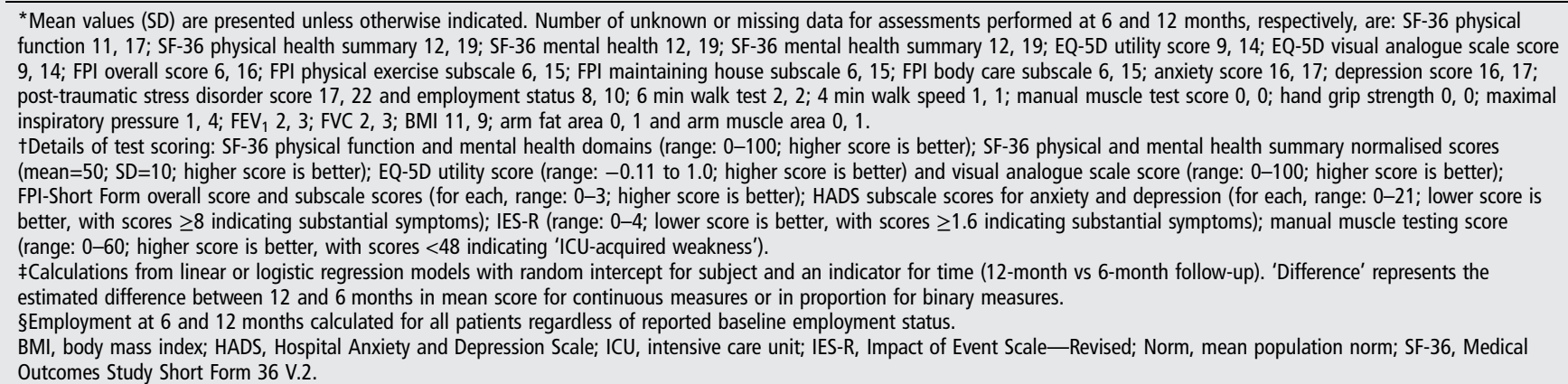 } \\
\hline
\end{tabular}

specification or power calculation conducted since the sample size was known to be dependent on the available patients at the participating sites during the eligible enrolment period.

Analyses were performed using SAS V.9.3 (SAS Institute, Cary, North Carolina, USA) using data from all eligible consenting survivors according to an a priori written statistical analysis plan, with missing data excluded given a low rate of missingness for the patient-reported primary outcomes. A two-sided $\mathrm{p}<0.05$ was considered significant.

\section{RESULTS}

The sites participating in this follow-up study recruited 568 patients, of which 293 (52\%) were randomised to rosuvastatin. Of the 568 patient cohort, 154 (27\%) died prior to discharge from hospital or after discharge before reconsent for follow-up, and $142(25 \%)$ met exclusion criteria, leaving 272 patients consented for follow-up (figure 1). These 272 patients had a mean (SD) age of 51 (15) years, 53\% women, 88\% living at home independently, $72 \%$ with $\mathrm{PaO}_{2} / \mathrm{FiO}_{2}$ ratio $\leq 200$ and $39 \%$ with shock. The baseline characteristics of the rosuvastatin versus placebo groups were generally similar for this cohort and the entire SAILS cohort $(\mathrm{N}=745)$, overall ALTOS cohort $(\mathrm{N}=568)$ and the ALTOS subgroup enrolled for in-person physical assessments $(\mathrm{N}=84)$ (table 1 and online supplementary table $\mathrm{S} 1)$.

\section{Patient outcomes at 6 and 12 months for all patients}

Over 12-month follow-up, the cumulative mortality rate for all 568 ALTOS participants was 41\%. At 6-month and 12-month 
Figure 2 Survival until 12 months after randomisation. This

figure illustrates the proportion of patients surviving in the study over time for the 568 patients in the ARDSNet Long-Term Outcomes Study cohort, with those who were alive, but excluded from follow-up, censored at hospital discharge. One consenting patient was censored at the 6-month assessment due to loss to follow-up thereafter. Patients who were known to be alive, but missed their 12-month follow-up assessment, were censored at the expected date of their 12-month assessment. The cumulative 1-year survival rate for rosuvastatin versus placebo was $58 \%$ vs $61 \%(p=0.377)$.

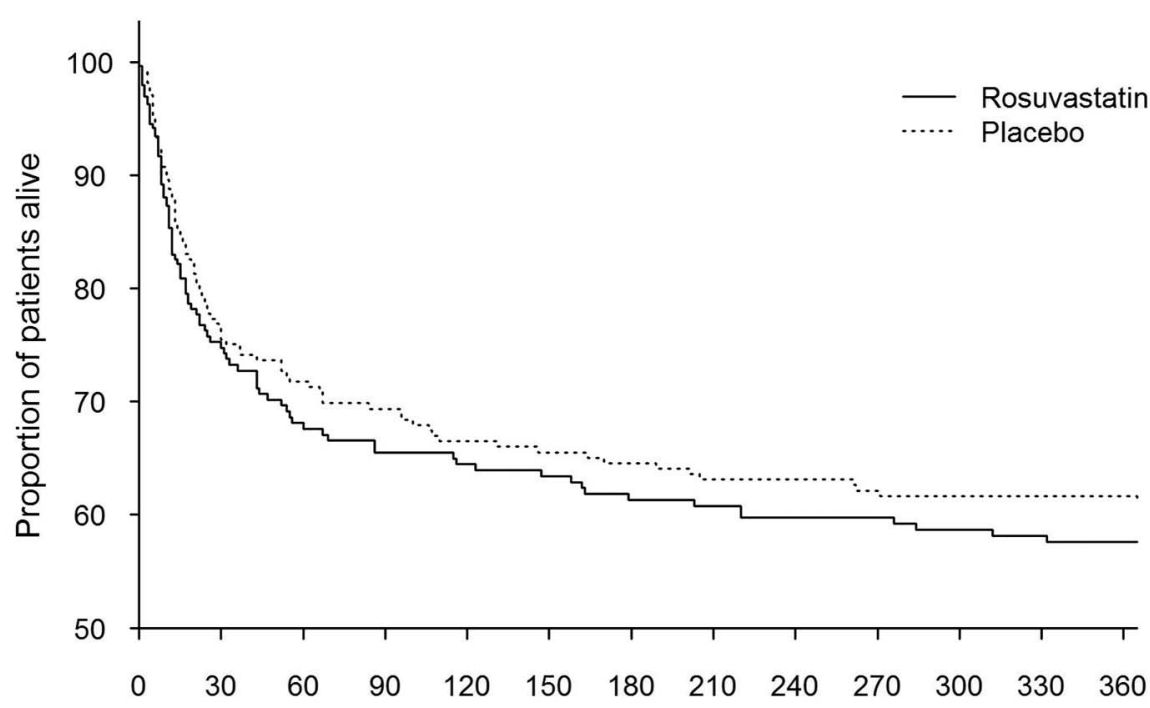

Time from randomisation (days)

$\begin{array}{rllllllllllll}\begin{array}{c}\text { Number at risk } \\ \text { Rosuvastatin } 293\end{array} & 150 & 132 & 126 & 124 & 122 & 118 & 116 & 115 & 115 & 112 & 111 & 110 \\ \text { Placebo } 275 & 168 & 151 & 145 & 139 & 137 & 135 & 132 & 132 & 130 & 129 & 129 & 129 \\ \text { Number of deaths } & & & & & & & & & & & & \\ \text { Rosuvastatin } & 65 & 14 & 4 & 2 & 2 & 4 & 1 & 2 & 0 & 2 & 1 \\ \text { Placebo } & 61 & 8 & 5 & 6 & 2 & 2 & 3 & 0 & 2 & 1 & 0 & 0\end{array}$

follow-up, respectively, 238 and 237 survivors were eligible for follow-up, and 233 (98\%) and 220 (93\%) were assessed (figure 1). At 6-month follow-up, patients had significantly lower SF-36 physical and mental health domain scores compared with age-matched and sex-matched population norms (table 2). Functional activities, measured by the FPI, had a mean (SD) overall score of $1.9(0.7)$, signifying 'some difficulty' with activities (table 2). At 6 months, mental health symptoms were also common, with $46 \%, 37 \%$ and $25 \%$ of patients having substantial symptoms of anxiety, depression and PTSD, respectively. Between 6-month and 12-month follow-up, there was little evidence of clinically and statistically significant improvements in these outcomes (table 2). In terms of employment, $19 \%$ and $24 \%$ of survivors were working at 6 and 12 months; and of those employed prior to hospitalisation for ARDS, $43 \%$ and $46 \%$ had returned to work at 6 and 12 months, respectively.

In the subset of patients completing the performance-based physical assessments (see table 2 and online supplementary figure 1), the mean (SD) per cent predicted value for the 6 min walk test, at 6 and 12 months, was 65\% (24\%) and 71\% (23\%), respectively $(\mathrm{p}=0.001$ for increase over time). ICU-acquired weakness (manual muscle test score $<48$ out of 60 ) occurred in three (4\%) and one (2\%) patient at 6 and 12 months, respectively. Mean (SD) values for other physical assessments, evaluated as per cent predicted values at 6 and 12 months, were: hand grip strength (83\% (29\%) and 91\% (32\%), $\mathrm{p}=0.001$ for increase over time) and maximal inspiratory pressure $(85 \%$ $(32 \%)$ and 98\% (32\%), $\mathrm{p}<0.001)$.

\section{Rosuvastatin versus placebo}

Over 12-month follow-up, there was no significant difference in survival across the treatment groups, with an estimated proportion of patients surviving to 12 months for rosuvastatin versus placebo of $58 \%$ vs $61 \%(\mathrm{p}=0.377$; figure 2$)$. At 6 -month follow-up, there also was no significant difference in mean (SD)
SF-36 physical function domain score for rosuvastatin versus placebo (51 (32) vs 47 (32)), with an age-adjusted and sexadjusted mean difference $(95 \% \mathrm{CI})$ of $0((-7$ to 8$) ; \mathrm{p}=0.939)$. Similarly, there was no difference in the mean (SD) SF-36 mental health domain score: 38 (12) vs 36 (12) (adjusted difference: $-6(-12$ to 1$), p=0.496)$, or in any other patient-reported outcome (table 3 and figure 3 ).

For the performance-based physical assessments, at 6-month follow-up, there was no significant difference in the primary outcome of mean (SD) 6 min walk test per cent predicted value for rosuvastatin versus placebo $(65 \%(22 \%)$ vs $64 \%(25 \%))$, with a mean difference $(95 \% \mathrm{CI})$ of $2 \%((-9 \%$ to $14 \%$; $\mathrm{p}=0.679)$. There also was no significant difference in the other physical performance tests evaluated (table 3 and figure 3).

The preceding results for patient-reported outcomes and physical assessments at 6 months were similar with 12-month assessments and with all sensitivity analyses (as described in the Methods section), including no significant effect of statins on patient recovery between 6-month and 12-month follow-up. Moreover, across the a priori subgroup analyses (as described in the Methods section), there were no significant differences, except as reported herein. First, at 6-month and 12-month follow-up, in patients with BMI $<30 \mathrm{~kg} / \mathrm{m}^{2}$, rosuvastatin patients had a greater odds of substantial symptoms of anxiety (HADS anxiety score $\geq 8$ ) compared with placebo, but no significant difference in anxiety symptoms modelled as a continuous outcome. Second, at 6-month and 12-month follow-up, in patients with $\mathrm{PaO}_{2} / \mathrm{FiO}_{2} \leq 200$, the rosuvastatin group had a greater odds of substantial symptoms of depression (HADS depression score $\geq 8$ ), but no significant difference in depression symptoms modelled as a continuous outcome. Third, at 12-month follow-up (only), in patients with a greater difficulty in performing activities at baseline (ie, lower FPI score prior to ARDS), the rosuvastatin group had lower mean grip strength. Fourth, at both 6 and 12 months, in patients with higher 
Table 3 Six-month results by randomised treatment group*

\begin{tabular}{|c|c|c|c|c|}
\hline Domain-survey instrument $\dagger$ & Rosuvastatin $(n=109)$ & Placebo $(n=124)$ & Treatment effect $¥(95 \% \mathrm{CI})$ & p Value \\
\hline \multicolumn{5}{|l|}{ Quality of life-Short Form-36 (population norm) } \\
\hline Physical function (norm: 81 (10))§ & $51(32)$ & $47(32)$ & $0(-7$ to 8$)$ & 0.939 \\
\hline Physical health summary (norm: 50 (10)) & $38(12)$ & $36(12)$ & $1(-2$ to 4$)$ & 0.496 \\
\hline Mental health (norm: $76(3)) \S$ & $62(25)$ & $66(26)$ & $-6(-12$ to 1$)$ & 0.085 \\
\hline Mental health summary (norm: 50 (10)) & $43(15)$ & $46(15)$ & $-3(-7$ to 1$)$ & 0.093 \\
\hline \multicolumn{5}{|l|}{ Quality of life-EQ-5D } \\
\hline Utility score & $0.69(0.24)$ & $0.67(0.23)$ & $0.02(-0.05$ to 0.08$)$ & 0.573 \\
\hline Visual analogue scale & $68(22)$ & $65(23)$ & $4(-2$ to 9$)$ & 0.233 \\
\hline \multicolumn{5}{|c|}{ Functional activities-Functional Performance Inventory-Short Form } \\
\hline Overall score & $1.9(0.8)$ & $1.9(0.7)$ & $-0.1(-0.3$ to 0.1$)$ & 0.437 \\
\hline Physical exercise subscale & $1.4(0.9)$ & $1.5(0.8)$ & $-0.1(-0.3$ to 0.1$)$ & 0.394 \\
\hline Maintaining house subscale & $1.7(1.0)$ & $1.7(1.0)$ & $-0.1(-0.3$ to 0.2$)$ & 0.684 \\
\hline Body care subscale & $2.4(0.8)$ & $2.5(0.6)$ & $-0.1(-0.3$ to 0.0$)$ & 0.121 \\
\hline \multicolumn{5}{|l|}{ Mental health symptoms } \\
\hline Anxiety score-HADS & $8(5)$ & $7(5)$ & $1(-1$ to 2$)$ & 0.373 \\
\hline Anxiety $\geq 8$, No (\%) & $48(48)$ & $52(44)$ & $1 \%(1$ to 2$)$ & 0.588 \\
\hline Depression score-HADS & $6(5)$ & $6(5)$ & $0(-1$ to 2$)$ & 0.744 \\
\hline Depression $\geq 8$, No (\%) & $39(39)$ & $42(36)$ & $1 \%(1$ to 2$)$ & 0.621 \\
\hline Post-traumatic stress disorder score-IES-R & $1.1(0.9)$ & $1.0(1.0)$ & $0.1(-0.2$ to 0.3$)$ & 0.606 \\
\hline Post-traumatic stress disorder $\geq 1.6$, no. (\%) & $27(27)$ & $28(24)$ & $1 \%(1$ to 2$)$ & 0.744 \\
\hline Employed, no. (\%)§ & $20(19)$ & $22(18)$ & $1 \%(0$ to 2$)$ & 0.940 \\
\hline Performance-based physical outcomest & Rosuvastatin $(n=28)$ & Placebo $(n=39)$ & Treatment effect $\ddagger(95 \% \mathrm{CI})$ & p Value $\ddagger$ \\
\hline 6 min walk distance, $\%$ predicted & $65(22)$ & $64(25)$ & $2(-9$ to 14$)$ & 0.679 \\
\hline $4 \mathrm{~m}$ gait speed $(\mathrm{m} / \mathrm{s})$ & $0.9(0.2)$ & $1.0(0.3)$ & $-0.1(-0.2$ to 0.1$)$ & 0.477 \\
\hline Manual muscle test score & $57(3)$ & $56(4)$ & $1(-1$ to 3$)$ & 0.201 \\
\hline Hand grip strength, $\%$ predicted & $83(34)$ & $83(26)$ & $1(-14$ to 15$)$ & 0.926 \\
\hline Maximal inspiratory pressure, $\%$ predicted & $85(31)$ & $85(34)$ & $-1(-17$ to 15$)$ & 0.889 \\
\hline $\mathrm{FEV}_{1} \%$ predicted & $78(17)$ & $76(23)$ & $3(-7$ to 13$)$ & 0.545 \\
\hline FVC $\%$ predicted & $79(18)$ & $76(21)$ & $4(-6$ to 13$)$ & 0.433 \\
\hline $\mathrm{BMI}\left(\mathrm{kg} / \mathrm{m}^{2}\right)$ & $31(8)$ & $28(7)$ & $4(-1$ to 9$)$ & 0.084 \\
\hline Arm fat area, $\%$ & $36(14)$ & $35(11)$ & $1(-5$ to 7$)$ & 0.713 \\
\hline Arm muscle area, $\%$ & $54(11)$ & $53(9)$ & $1(-3$ to 6$)$ & 0.551 \\
\hline \multicolumn{5}{|c|}{ 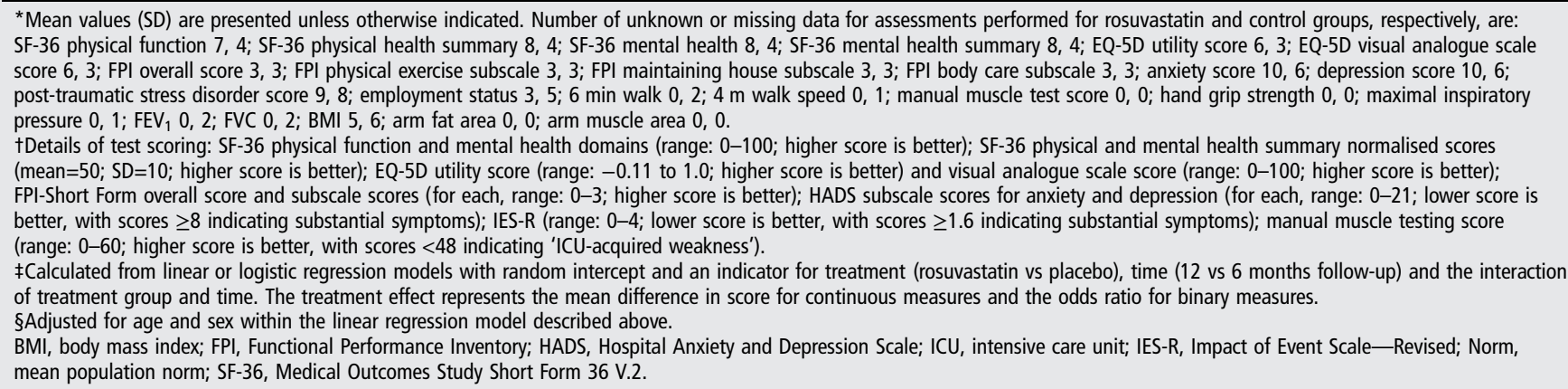 } \\
\hline
\end{tabular}

number of comorbid conditions (ie, higher Functional Comorbidity Index score prior to ARDS), the rosuvastatin group had higher mean BMI and arm fat percentage than the control group. Lastly, there was no benefit of rosuvastatin versus placebo in the primary outcomes when comparing those in highest quartile decrease of CRP versus those in the lowest quartile. Post-hoc sensitivity analysis accounting for clustering by study hospital demonstrated no qualitative change in results from the primary analysis.

\section{DISCUSSION}

In this 12-month, prospective follow-up study of 568 patients with sepsis-associated ARDS participating in the SAILS trial of rosuvastatin versus placebo, cumulative mortality was $41 \%$, with the 272 survivors' physical functioning and performance and mental health status being below predicted values. Despite the known associations of statin use with neuromuscular and mental health side effects, in this randomised trial, randomisation to rosuvastatin did not affect survival, physical functioning and performance, or mental health outcomes at 6 and 12 months after ARDS.

\section{Comparison with other studies}

The physical and mental health impairments reported in this study are similar to a prior national cohort of 563 ARDS survivors from ARDSNet's EDEN trial. ${ }^{18} 19$ These impairments also were similar to prior smaller studies of ARDS survivors. ${ }^{10} 3839$ 
Figure 3 Forest plotpatient-reported and performance-based physical outcomes. This figure illustrates the treatment effect for rosuvastatin versus placebo, presented as an effect size, with 95\% $\mathrm{Cl}$, for the primary outcome (age-adjusted and sex-adjusted SF-36 physical function and mental health domains and 6 min walk test per cent predicted) and all secondary outcomes. Effect size was calculated as the treatment effect (table 3, difference in means or proportions) divided by the pooled SD from the rosuvastatin and placebo groups. ${ }^{49} 50$ HADS, Hospital Anxiety and Depression Scale; IES-R, Impact of Event Scale-Revised.

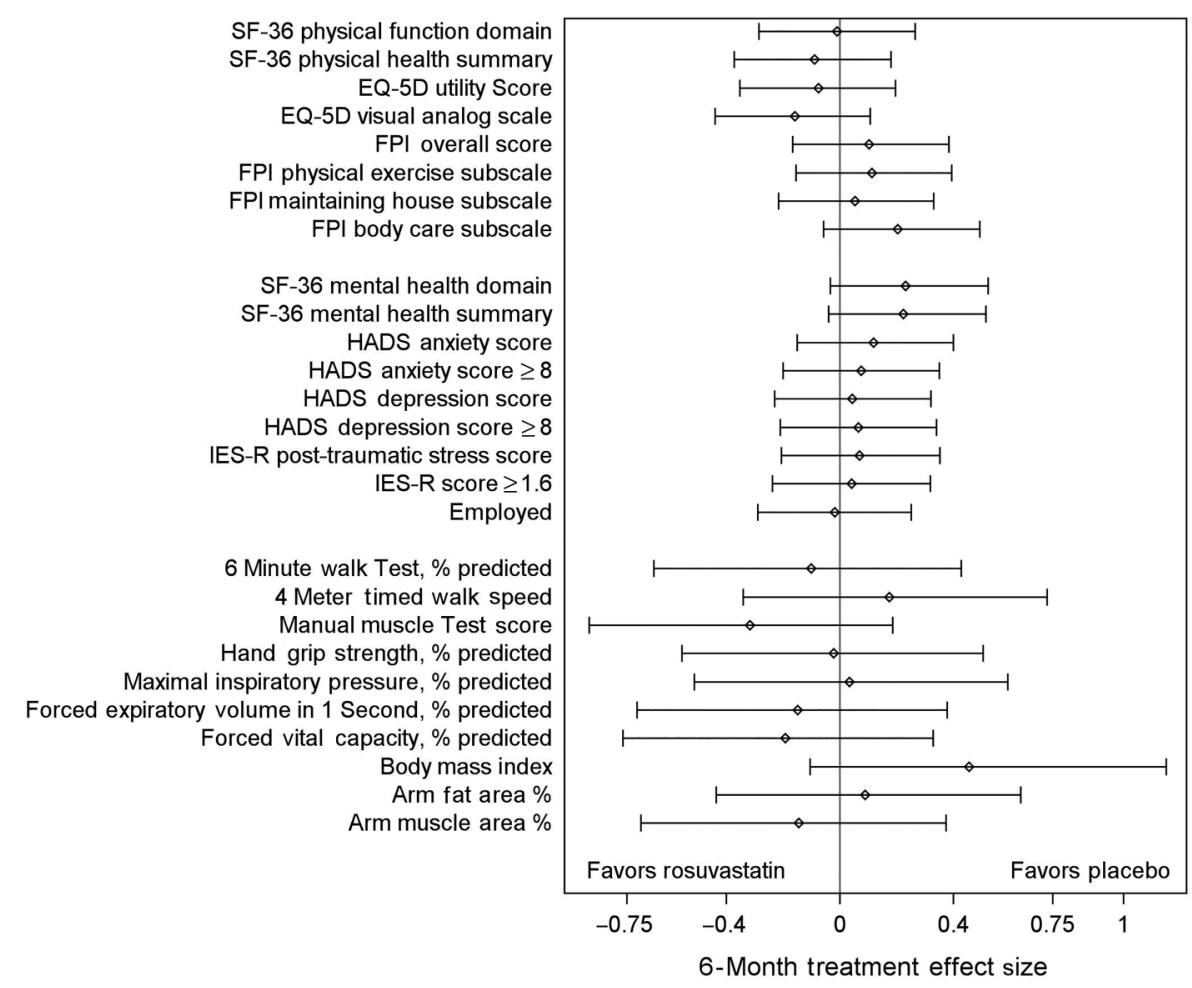

Within this study, patient-reported physical outcomes may appear discordant with performance-based outcomes, consistent with previous studies demonstrating a lack of strong correlation between patient-reported physical function and performancebased measures. ${ }^{40}$ Therefore, there is need for continued investigation into interventions that may reduce post-ICU physical and mental health impairments experienced by the growing number of ICU survivors, ${ }^{41}$ and to consider use of both patient-reported and performance-based outcome measures.

This study found no negative or positive effects of rosuvastatin on physical function and performance or mental health outcomes at 6-month and 12-month follow-up. There are several possible explanations. First, these findings may be attributable to the relatively short duration of rosuvastatin exposure (median of 9 days) in SAILS. ${ }^{1}$ Second, rosuvastatin may have had shorter-term effects that did not persist until the initial 6-month follow-up assessment in this study, given that statin-associated myopathy, behavioural problems and mood disorders may resolve within weeks to months after medication cessation. ${ }^{9}$ Lastly, rosuvastatin's hydrophilic structure may impede crossing the blood-brain barrier, potentially decreasing any adverse effects observed for other more lipophilic statins. For example, the majority of statin-associated behavioural and mood disorders have been reported with the lipophilic statins, simvastatin and atorvastatin. ${ }^{9}$

The lack of negative effects of rosuvastatin, a hydrophilic statin, at 6 and 12 months in this study have clinical implications. For example, coupled with lack of short-term harm in a trial of simvastatin, a lipophilic statin in patients with ARDS, ${ }^{42}$ this study helps provide further reassurance of the safety of continuing pre-existing statin therapy during ICU. This finding is important given that stopping statins may be associated with rebound in inflammatory markers and loss of cardiovascularrelated protective effects. ${ }^{43} 44$

\section{Strengths and limitations}

This study has several strengths, including being the first large-scale, randomised trial of statins in critical illness to assess survival beyond 90 days, as well as to comprehensively assess key functional outcomes, such as physical and mental health status. However, there are potential limitations. First, the results may not be generalisable to all patients with ARDS since the SAILS trial enrolled a relatively young cohort of patients with sepsis-associated ARDS with less severe comorbidity due to enrolment screening. Second, outcomes may not be generalisable to the entire SAILS cohort since outcomes were measured only in a subset of patients, partly due to the competing risk of death. ${ }^{45}$ However, the available cohort for follow-up has similar baseline characteristics as the full cohort, with similar follow-up exclusion rates and mortality rates between treatment groups. Also, sensitivity analyses specifically addressing the competing risk of mortality did not result in any material change in the results. Third, this study could not prospectively measure patients' baseline status in order to understand new impairments arising after critical illness. However, baseline characteristics were similar between groups after randomisation with $88 \%$ of patients independently living at home, with evidence of new or worsening impairments after ARDS supported by $57 \%$ of previously employed patients not working at 6 months, $25 \%$ of participants reporting substantial PTSD symptoms specifically attributable to their ICU stay and a threefold increase in the proportion of participants reporting at least 'much' difficulty with basic functional activities for the patient subset that completed physical performance assessments. Moreover, prior studies, with prospective baseline assessments, have clearly demonstrated the incidence of new impairments across physical and mental health after critical illness. ${ }^{46}$ Fourth, there were missed assessments during longitudinal follow-up that may introduce bias. However, rates of missed follow-up assessments were similar between the randomised groups, and were very low $(\leq 3 \%)$ for the patient-reported outcomes at the 6-month primary outcome time-point. Moreover, there was little evidence to support a difference between rosuvastatin versus placebo in the primary outcome measures evaluating both patient-reported physical function $(\mathrm{p}=0.939)$ and performance-based physical assessment 
(0.679), suggesting that missing data would not materially change the conclusions made from this study. Finally, because the first outcome assessment occurred at 6 months after ARDS, we cannot rule out an undetected short-term effect of rosuvastatin on patients' physical or mental health outcomes. However, the focus of this study was specifically to evaluate for effects lasting beyond the short-term, as recommended by many professional and scientific organisations. ${ }^{4148}$

\section{CONCLUSION}

This prospective 12-month evaluation of 568 patients with sepsis-associated ARDS participating in the SAILS trial of rosuvastatin versus placebo demonstrated high cumulative mortality, with the 272 survivors commonly experiencing important impairments in physical functioning and performance and mental health status. Despite known side effects of statins on neuromuscular function and mental health, there was no evidence of harm or benefit of randomisation to rosuvastatin on survival, physical functioning and performance or mental health over 1-year follow-up.

\section{Author affiliations}

${ }^{1}$ Outcomes after Critical IIIness and Surgery (OACIS) Group, Johns Hopkins University, Baltimore, Maryland, USA

${ }^{2}$ Division of Pulmonary and Critical Care Medicine, Johns Hopkins University School of Medicine, Baltimore, Maryland, USA

${ }^{3}$ Pulmonary and Critical Care Division, Department of Medicine, Intermountain Medical Center, Murray, Utah, USA

${ }^{4}$ Psychology Department and Neuroscience Center, Brigham Young University, Provo, Utah, USA

${ }^{5}$ Center for Humanizing Critical Care, Intermountain Health Care, Murray, Utah, USA ${ }^{6}$ Department of Biostatistics, Bloomberg School of Public Health, Johns Hopkins University, Baltimore, Maryland, USA

${ }^{7}$ Division of Pulmonary and Critical Care Medicine, Harborview Medical Center, University of Washington, Seattle, Washington, USA

${ }^{8}$ Division of Pulmonary, Critical Care \& Sleep Medicine, University of Kentucky, Lexington, Kentucky, USA

${ }^{9}$ Division of Allergy, Pulmonary, and Critical Care Medicine, Department of Medicine, Vanderbilt University School of Medicine, Nashville, Tennessee, USA

${ }^{10}$ Department of Anesthesiology and Critical Care Medicine, Johns Hopkins University School of Medicine, Baltimore, Maryland, USA

${ }^{11}$ Department of Psychiatry and Behavioral Sciences, Johns Hopkins University School of Medicine, Baltimore, Maryland, USA

${ }^{12}$ Geriatric Research, Education and Clinical Center Service, Department of Veterans Affairs Medical Center, Tennessee Valley Healthcare System, Nashville, Tennessee, USA

${ }^{13}$ Department of Physical Medicine and Rehabilitation, Johns Hopkins University School of Medicine, Baltimore, Maryland, USA

Acknowledgements We thank all patients and their proxies who participated in the study. We acknowledge our dedicated research staff, including the following employees who assisted with data collection and management, and manuscript preparation: Ellen Caldwell, MS; Ashlee Case, MS; Lin Chen, BS; Caroline Chessare, BA; Nancy Ciesla, DPT, MS; Lori-Ann Flores, BSN; Stephanie Gundel, BS; Mohamed Hashem, MD; Melissa McCullough, BS; Jessica McCurley, MS; Mardee Merrill, BS; Mariela Pinedo, BS; Kyle Schneck, MA; Stacey Schoonmaker, BA; Kristin Sepulveda, BA; Marcella Shrout, MA; Elizabeth Vayda, MS and Cassie Wicken, BA. We also thank the ARDS Network and participating sites: University of Washington, Harborview Medical Center (C Hough (principal investigator), S Gundel, L Hudson, M Neff, C Johnson, K Sims, T Watkins); Providence-Everett Medical Center (S Lubatti, T Ziedalski); Swedish Medical Center (D Finch, S O'Mahony); Baystate Medical Center (J Steingrub (principal investigator), M Tidswell, L DeSouza, C Kardos, L Kozikowski, S Ouellette); Baylor College of Medicine (K Guntupalli, V Bandi, C Pope, C Ross); Johns Hopkins University (R Brower (principal investigator), H Fessler, D Hager, P Mendez-Tellez, D Needham, K Oakjones); Johns Hopkins Bayview Medical Center (J Sevransky, A Workneh); University of Maryland (C Shanholtz, D Herr, H Howes, G Netzer, P Rock, A Sampaio, J Titus); Union Memorial Hospital (P Sloane, T Beck, D Highfield, J Lehmann, H Luu); Franklin Memorial Hospital Center (S Selinger, S King); St Josephs Hospital of Baltimore (L Barr): Cleveland Clinic Foundation (HP Wiedemann (principal investigator), RW Ashton, DA Culver, M Ferrari, T Frederick, JA Guzman, JJ Komara Jr, AJ Reddy, R Schilz); University Hospitals of Cleveland (R Hejal, M Andrews, D Haney); MetroHealth Medical Center (AF Connors, S Lasalvia, JD Thornton, EL Warren); University of
Colorado Hospital, Aurora (M Moss (principal investigator), EL Burnham, L Gray, J Maloney, M Mealer); Denver Health Medical Center (I Douglas, K Overdier, B Thomas, K Thompson, R Wolken); Rose Medical Center (S Frankel, J McKeehan); Swedish Medical Center (ML Warner); Saint Anthony's Hospital (T Boe, T Bost, C Higgins, K Hodgin); Duke University (N Maclntyre (principal investigator), L Brown, C Cox, M Gentile, J Govert, N Knudsen); University of North Carolina (S Carson, L Chang, S Choudhury, J Lanier, J McGuire); Vanderbilt University (AP Wheeler (principal investigator), GR Bernard, M Hays, S Mogan, TW Rice); Wake Forest University (RD Hite (principal investigator), PE Morris, M. Ragusky, B Mirafuente); Moses Cone Memorial Hospital (P Wright, S Groce, J McLean, A Overton); University of Virginia ( $J$ Truwit, K Enfield, M Marshall); Intermountain Medical Center (A Morris (principal investigator), AC Grissom (principal investigator), A Austin, $S$ Brown, J Ferguson, H Gallo, T Graydon, J Dunn, E Hirshberg, A Jephson, N Kumar, M Lanspa, R Miller, D Murphy, J Orme, S Pies, A Stowe, L Struck, F Thomas, D Ward, J Wilson); LDS Hospital (P Bailey, W Beninati, L Bezdjian, T Clemmer, S Rimkus, R Tanaka, L Weaver); McKay-Dee Hospital (C Lawton, D Hanselman, J Jewkes); Utah Valley Regional Medical Center (K Sundar, W Alward, C Bishop, D Eckley, D Harris, T Hill, B Jensen, K Ludwig, D Nielsen, M Pearce); University of California, San Francisco (MA Matthay (principal investigator), CS Calfee, B Daniel, KD Liu, H Zhou); University of California, San Francisco, Fresno (MW Peterson, J Blaauw, K Van Gundy); University of California, Davis (T Albertson, B Morrissey, E Vlastelin); Stanford (J Levitt, E Kovoor, R Vojnik); Louisiana State University Health Sciences Center-New Orleans (B deBoisblanc (principal investigator), A Antoine, D Charbonnet, P Griffenstein, J Hunt, M Lammi, P Lauto, A Marr, G Meyaski, C Romaine) and Ochsner Clinic Foundation (S Jain, D Taylor, L Seoane). Steering Committee Chairman: Gordon R Bernard. Clinical Coordinating Center: Massachusetts General Hospital and Harvard Medical School (D Schoenfeld (principal investigator), A DeBenedictis, N Dong, E Hammond, A Lagakos, P Lazar, R Morse, C Oldmixon, N Ringwood, E Smoot, BT Thompson, R Wilson). National Heart, Lung and Blood Institute: A Harabin, S Bredow, M Waclawiw, G Weinmann. Data and Safety Monitoring Board: RG Spragg (chair), A Slutsky, M Levy, B Markovitz, E Petkova, C Weijer, D Willson.

Contributors VDD, DMN and ROH contributed to conception and design of the manuscript. VDD, ROH, AWW, CLH, PEM, JCJ, PAMT, OJB, EWE, EC and DMN contributed to analysis and interpretation of data. VDD drafted the manuscript and all other authors critically revised it for important intellectual content. All authors gave final approval of the manuscript version to be published. VDD and DMN are responsible for the overall content as guarantors and affirms that the manuscript is an honest, accurate and transparent account of the study being reported; that no important aspects of the study have been omitted and that any discrepancies from the study as planned (and, if relevant, registered) have been explained.

Funding National Heart, Lung and Blood Institute funded this follow-up study (N01HR56170, R01HL091760 and 3R01HL091760-02S1) and the Statins for Acutely Injured Lungs from Sepsis (SAILS) trial (contracts HHSN268200536165C to HHSN268200536176C and HHSN268200536179C), along with the Johns Hopkins Institute for Clinical and Translational Research (UL1 TR 000424-06). Additionally, the SAILS trial was supported by the Investigator-Sponsored Study Program of AstraZeneca. All researchers are independent of the funding bodies.

Competing interests None declared.

Ethics approval The Johns Hopkins University's Institutional Review Board (IRB) along with the IRBs of all participating sites have approved this study.

Provenance and peer review Not commissioned; externally peer reviewed.

\section{REFERENCES}

1 Truwit JD, Bernard GR, Steingrub J, et al. Rosuvastatin for sepsis-associated acute respiratory distress syndrome. N Engl J Med 2014;370:2191-200.

2 Craig TR, Duffy MJ, Shyamsundar M, et al. A randomized clinical trial of hydroxymethylglutaryl-coenzyme a reductase inhibition for acute lung injury (The HARP Study). Am J Respir Crit Care Med 2011;183:620-6.

3 El Gendy HA, Elsharnouby NM. Safety and vasopressor effect of rosuvastatin in septic patients. Egyptian Journal of Anaesthesia 2014;30:311-17.

4 Prado K, Ribeiro C, Furian T, et al. A clinical randomized trial on the use of atorvastatin in patients with sepsis or septic shock: Effects on endothelial function. Crit Care 2013:17:S22

5 Thomas G, Hraiech S, Loundou A, et al. Statin therapy in critically-ill patients with severe sepsis: a review and meta-analysis of randomized clinical trials. Minerva Anestesiol 2015;81:921-30.

6 Simic I, Reiner Z. Adverse effects of statins-myths and reality. Curr Pharm Des 2015;21:1220-6.

7 Hough C, Ney J, Miller R, et al. Randomization to rosuvastatin is associated with neuromyopathy in patients with ARDS. Am J Respir Crit Care Med 2015;191:A2281

8 Batt J, dos Santos CC, Cameron Jl, et al. Intensive care unit-acquired weakness: clinical phenotypes and molecular mechanisms. Am J Respir Crit Care Med 2013;187:238-46. 
9 Tuccori M, Montagnani S, Mantarro S, et al. Neuropsychiatric adverse events associated with statins: epidemiology, pathophysiology, prevention and management. CNS Drugs 2014;28:249-72.

10 Bienvenu OJ, Colantuoni E, Mendez-Tellez PA, et al. Depressive symptoms and impaired physical function after acute lung injury: a 2-year longitudinal study. Am J Respir Crit Care Med 2012;185:517-24.

11 Davydow DS, Desai SV, Needham DM, et al. Psychiatric morbidity in survivors of the acute respiratory distress syndrome: a systematic review. Psychosom Med 2008;70:512-19.

12 Parker AM, Sricharoenchai T, Raparla $S$, et al. Posttraumatic stress disorder in critical illness survivors: a meta-analysis. Crit Care Med 2015;43:1121-9.

13 Zeiher BG, Artigas A, Vincent JL, et al. Neutrophil elastase inhibition in acute lung injury: results of the STRIVE study. Crit Care Med 2004;32:1695-702.

14 Angus DC, Laterre PF, Helterbrand J, et al. The effect of drotrecogin alfa (activated) on long-term survival after severe sepsis. Crit Care Med 2004;32:2199-206.

15 Winters BD, Eberlein $\mathrm{M}$, Leung J, et al. Long-term mortality and quality of life in sepsis: a systematic review. Crit Care Med 2010;38:1276-83.

16 Lone NI, Walsh TS. Impact of intensive care unit organ failures on mortality during the five years after a critical illness. Am J Respir Crit Care Med 2012;186:640-7.

17 Hermans G, Van Mechelen H, Clerckx B, et al. Acute outcomes and 1-year mortality of intensive care unit-acquired weakness. A cohort study and propensity-matched analysis. Am J Respir Crit Care Med 2014;190:410-20.

18 Needham DM, Dinglas VD, Bienvenu OJ, et al. One year outcomes of initial trophic vs full enteral feeding in acute lung injury patients: prospective follow-up of the EDEN randomized trial. BMJ 2013;346:f1532.

19 Needham DM, Dinglas VD, Morris PE, et al. Physical and cognitive performance of patients with acute lung injury 1 year after initial trophic versus full enteral feeding. EDEN trial follow-up. Am J Respir Crit Care Med 2013;188:567-76.

20 Rice TW, Wheeler AP, Thompson BT, et al. Initial trophic vs full enteral feeding in patients with acute lung injury: the EDEN randomized trial. JAMA 2012;307:795-803.

21 Robinson KA, Dinglas VD, Sukrithan V, et al. Updated systematic review identifies substantial number of retention strategies: using more strategies retains more study participants. J Clin Epidemiol 2015;68:1481-7.

22 Groll DL, To T, Bombardier C, et al. The development of a comorbidity index with physical function as the outcome. J Clin Epidemiol 2005;58:595-602.

23 Ware JE, Jr., Kosinski M, Dewey JE. How to Score Version 2 of the SF-36 Health Survey. Lincoln, Rl: QualityMetric Incorporated, 2000.

24 The EuroQol Group. EuroQol-a new facility for the measurement of health-related quality of life. Health Policy 1990;16:199-208.

25 Shaw JW, Johnson JA, Coons SJ. US valuation of the EQ-5D health states: development and testing of the D1 valuation model. Med Care 2005;43:203-20.

26 Leidy NK. Psychometric properties of the functional performance inventory in patients with chronic obstructive pulmonary disease. Nurs Res 1999;48:20-8.

27 Zigmond AS, Snaith RP. The hospital anxiety and depression scale. Acta Psychiatr Scand 1983:67:361-70.

28 Bienvenu JB, Williams JB, Yang A, et al. Posttraumatic stress disorder in acute lung injury survivors: evaluating the Impact of Event Scale-Revised. Chest 2013;144:24-31.

29 Enright PL, Sherrill DL. Reference equations for the six-minute walk in healthy adults. Am J Respir Crit Care Med 1998;158(Pt 1):1384-7.
30 Guralnik JM, Ferrucci L, Pieper CF, et al. Lower extremity function and subsequent disability: consistency across studies, predictive models, and value of gait speed alone compared with the short physical performance battery. J Gerontol A Biol Sci Med Sci 2000;55:M221-31.

31 De Jonghe $B$, Sharshar $T$, Lefaucheur JP, et al. Paresis acquired in the intensive care unit: a prospective multicenter study. JAMA 2002;288:2859-67.

32 Mathiowetz V, Kashman N, Volland G, et al. Grip and pinch strength: normative data for adults. Arch Phys Med Rehabil 1985;66:69-74.

33 Harik-Khan Rl, Wise RA, Fozard JL. Determinants of maximal inspiratory pressure. The Baltimore Longitudinal Study of Aging. Am J Respir Crit Care Med 1998;158(Pt 1):1459-64.

34 Hankinson JL, Odencrantz JR, Fedan KB. Spirometric reference values from a sample of the general U.S. population. Am J Respir Crit Care Med 1999;159:179-87.

35 Frisancho AR. Anthropometric Standards for the Assessment of Growth and Nutritional Status. Ann Arbor, MI: The University of Michigan Press, 1990.

36 Harrell FE. Regression modeling strategies: with applications to linear models, logistic and ordinal regression, and survival analysis. Secaucus, NJ: Springer-Verlag New York Inc., 2006.

37 Lachin JM. Worst-rank score analysis with informatively missing observations in clinical trials. Control Clin Trials 1999;20:408-22.

38 Fan E, Dowdy DW, Colantuoni E, et al. Physical complications in acute lung injury survivors: a two-year longitudinal prospective study. Crit Care Med 2014;42:849-59.

39 Herridge MS, Cheung AM, Tansey CM, et al. One-year outcomes in survivors of the acute respiratory distress syndrome. N Engl J Med 2003;348:683-93.

40 Needham DM, Wozniak AW, Hough CL, et al. Risk factors for physical impairment after acute lung injury in a national, multicenter study. Am J Respir Crit Care Med 2014; 189:1214-24.

41 Needham DM, Davidson J, Cohen H, et al. Improving long-term outcomes after discharge from intensive care unit: report from a stakeholders' conference. Crit Care Med 2012;40:502-9.

42 McAuley DF, Laffey JG, O'Kane CM, et al. Simvastatin in the acute respiratory distress syndrome. N Engl J Med 2014;371:1695-703.

43 Lee KT, Lai WT, Chu CS, et al. Effect of withdrawal of statin on C-reactive protein. Cardiology 2004;102:166-70.

44 Heeschen C, Hamm CW, Laufs $U$, et al. Withdrawal of statins increases event rates in patients with acute coronary syndromes. Circulation 2002;105:1446-52.

45 Varadhan $\mathrm{R}$, Weiss CO, Segal JB, et al. Evaluating health outcomes in the presence of competing risks: a review of statistical methods and clinical applications. Med Care 2010;48(6 Suppl):S96-105.

46 Barnato $A E$, Albert SM, Angus DC, et al. Disability among elderly survivors of mechanical ventilation. Am J Respir Crit Care Med 2011;183:1037-42.

47 Davydow DS, Hough CL, Russo JE, et al. The association between intensive care unit admission and subsequent depression in patients with diabetes. Int J Geriatr Psychiatry 2012;27:22-30.

48 Spragg RG, Bernard GR, Checkley W, et al. Beyond mortality: future clinical research in acute lung injury. Am J Respir Crit Care Med 2010;181:1121-7.

49 Steiger JH, Fouladi RT. Noncentrality interval estimation and the evaluation of statistical models. In: Harlow LL, Mulaik SA, Steiger JH, eds. What if there were no significance tests? Mahwah, NJ: Erlbaum, 1997:221-58.

50 Hedges LV, Olkin I. Statistical methods for meta-analysis. San Diego, CA: Academic Press, 1985. 